\title{
Elastoplastic Analysis of Coupling Mechanism for River-crossing Tunnel under Seepage Condition
}

\author{
Junling Qiu ${ }^{a}$, Jinxing Lai ${ }^{b}$ \\ School of Highway, Chang'an University, Xi'an, Shaanxi, 710064, China \\ aemail: 870133597@qq.com, bemail: 373159626@qq.com
}

Keywords: High Water Pressure; River-crossing Tunnel; Elastoplastic Analysis

\begin{abstract}
Recently, the water environment, especially the investigation on the influence mechanism of high water pressure or water seepage on the tunnel stability is not thorough. In this study, based on the theory of seepage mechanics and elastic-plastic theory, the stress state of tunnel rock mass under the coupling of seepage field and stress field is analyzed, the formula for calculating the radius of plastic zone, the stress and displacement of the rock mass in the elastic-plastic state are derived. The stress and displacement of tunnel surrounding rock and the mechanical characteristics of the supporting structure are analyzed under the condition of seepage.
\end{abstract}

\section{Introduction}

With the rapid development of underground engineering, groundwater is almost always accompanied by underground engineering, groundwater preventing problem has plagued engineering field. Underground work in the confined water, groundwater control is more complex, the problem becomes more and more prominent. In recent years, our country built a large number of mountain tunnel, cross river tunnel, mine tunnel and all kinds of underground engineering, the tunnel will be excavated with complex geological environment. These tunnels have most of the groundwater with a certain pressure. In order to ensure the construction safety of tunnel, the tunnel construction encountered in the process of high pressure groundwater must be controlled and grooming.

For the water hydraulic tunnel, tunnel lining structure is subjected to the hydrodynamic pressure load inside tunnel and water pressure outside tunnel liner. For the non-hydraulic pressure tunnel, water pressure does not exist, there is only the external water pressure. Because the sealing impervious tunnel liner is not absolute, so the effect of water pressure on tunnel liner is the liner surface force and liner seepage volume force. Because the tunnel liner and the rock mass are permeable media, it can be considered that the movement of water seepage between the liner and the rock mass is continuous. In many cases, the tunnel liner and rock mass is not completely closed, there are pores, due to the existence of pores in the volume force of tunnel rock mass will not be directly transferred to the tunnel liner, this part becomes an independent structure to withstand water pressure.

At present, the water environment, especially the investigation on the influence mechanism of high water pressure or water seepage on the tunnel stability is not thorough. The high pressure tunnel with complicated hydrogeological conditions or river tunnel construction under the influence of seepage field and stress field coupling model is not perfect, which cannot fully reflect the seepage field and the stress field in the high pressure. In this paper, based on the coupling theory of seepage field and stress field, the interaction between rock mass and tunnel liner was analyzed. The research results can provide important guidance for underwater tunnels and mountain tunnels.

\section{Model Establishment}

In this study, the circular tunnel is taken as the research object. The following assumptions are considered in this model: tunnel diameter is $a$, the pore water pressure of the tunnel wall is $P_{1}$, the vertical distance from the tunnel center to the riverbed is $b$, and the far-field water pressure is $P_{0}$. It is assumed that the initial stress of rock mass is the self-weight stress, the lateral pressure 
coefficient is 1 , and the tunnel rock mass is homogeneous and isotropic. No gravity is considered in calculation, and the calculation model of the tunnel under seepage condition is shown in Figure 1.

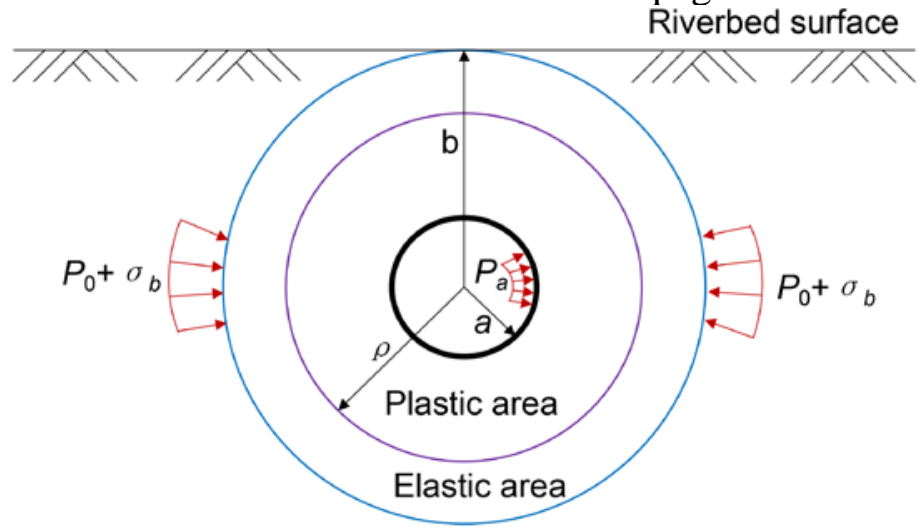

Figure 1. Calculation model of the tunnel under seepage condition

\section{Pore Water Pressure Distribution Law}

It is assumed that the tunnel rock mass is homogeneous and isotropic elastic medium, and the permeability coefficient of surrounding rock is the same in every direction. Without considering the self-weight of water, the seepage problem is simplified as axisymmetric steady flow problem. According to Darcy law and boundary conditions, the values of pore water pressure along the radial direction of the tunnel are obtained:

$$
P=P_{1}+\left(P_{0}-P_{1}\right) \frac{\ln \frac{a}{r}}{\ln \frac{a}{b}}(a \leq r \leq b)
$$

\section{Basic Equations and Boundary Conditions}

The equilibrium equations of water seepage are as follows:

Geometric equation is:

$$
\frac{d \sigma_{r}}{d r}+\eta \frac{d P}{d r}+\frac{\sigma_{r}-\sigma_{\theta}}{r}=0
$$

Physical equation is:

$$
\left.\begin{array}{c}
\varepsilon_{r}=\frac{d_{u}}{d_{r}}, \varepsilon_{\theta}=\frac{u}{r}, \gamma_{r \theta}=0 \\
\varepsilon_{r}=\frac{1-\mu^{2}}{E}\left(\sigma_{r}-\frac{\mu}{1-\mu} \sigma_{\theta}\right) \\
\varepsilon_{\theta}=\frac{1-\mu^{2}}{E}\left(\sigma_{\theta}-\frac{\mu}{1-\mu} \sigma_{r}\right)
\end{array}\right\}
$$

Boundary condition is:

$$
\left.\begin{array}{l}
\left.\sigma_{r}\right|_{r=b}=\sigma_{0}+P_{0} \\
\left.\sigma_{r}\right|_{r=\rho}=\sigma_{r}^{\rho}
\end{array}\right\}
$$

\section{Elastoplastic Solution of Stress and Displacement of Tunnel Rock Mass}

After the completion of the tunnel, the seepage of groundwater is mainly radial, and the buoyancy of seepage is smaller in the volume force. Therefore, the water's buoyancy to the rock mass is ignored, and the influence of seepage on the stress and displacement of surrounding rock is analyzed. The stress and displacement of rock mass are calculated by using the axisymmetric plane 
strain problem.

Stress and relative displacement formula of rock mass in elastic zone are:

$$
\begin{aligned}
& \sigma_{r}^{e}=\sigma_{b}+P_{0}+\frac{F}{2}\left(1+v_{1}\right) \ln \frac{r}{b}+\frac{\rho^{2} D}{\rho^{2}-b^{2}}\left(\frac{b^{2}}{r^{2}}-1\right) \\
& \sigma_{\theta}^{e}=\sigma_{b}+P_{0}+\frac{F}{2}\left[\left(1+v_{1}\right) \ln \frac{r}{b}+\left(v_{1}-1\right)\right]-\frac{\rho^{2} D}{\rho^{2}-b^{2}}\left(\frac{b^{2}}{r^{2}}+1\right) \\
& u_{e}^{\prime}=C_{1} r+\frac{C_{2}}{r}+\frac{F v}{2 E} r \ln r-\frac{r(1+\mu)(1-2 \mu)}{E}\left(\sigma_{b}+P_{0}\right)
\end{aligned}
$$

where $v=\frac{(1+\mu)(1-2 \mu)}{1-\mu}, F=\frac{\eta\left(P_{0}-P_{1}\right)}{\ln \left(\frac{a}{b}\right)}, v_{1}=\frac{\mu}{1-\mu}, \eta$ is the effective pore water pressure coefficient.

$$
\begin{aligned}
& C_{1}=\left(\sigma_{b}+P_{0}\right) \frac{v}{E\left(1+v_{1}\right)}-\left(\sigma_{b}+P_{0}-\sigma_{r}^{\rho}\right) \frac{\rho^{2}}{\rho^{2}-b^{2}} \frac{v}{E\left(1+v_{1}\right)}-\frac{F v}{2 E} \frac{\rho^{2}}{\rho^{2}-b^{2}} \ln \frac{\rho}{b} \\
& -\frac{F v}{2 E\left(1+v_{1}\right)}-\frac{F v}{2 E} \ln b \\
& C_{2}=\left(\sigma_{b}+P_{0}-\sigma_{r}^{\rho}\right) \frac{b^{2} \rho^{2}}{\rho^{2}-b^{2}} \frac{v}{E\left(v_{1}-1\right)}+\frac{F v}{2 E} \frac{b^{2} \rho^{2}}{\rho^{2}-b^{2}} \frac{v_{1}+1}{v_{1}-1} \ln \frac{\rho}{b} \\
& D=\left[\sigma_{b}+P_{0}-\sigma_{r}^{\rho}+\frac{F}{2}\left(1+v_{1}\right) \ln \frac{\rho}{b}\right]
\end{aligned}
$$

Stress and relative displacement in plastic zone are:

$$
\begin{aligned}
& \sigma_{r}^{p}=\frac{F(1-\sin \varphi)+2 c \cos \varphi}{2 \sin \varphi}\left[\left(\frac{r}{a}\right)^{\frac{2 \sin \varphi}{1-\sin \varphi}}-1\right]+\left(\frac{r}{a}\right)^{\frac{2 \sin \varphi}{1-\sin \varphi}} P_{a} \\
& \sigma_{\theta}^{p}=\frac{1+\sin \varphi}{1-\sin \varphi} \frac{F(1-\sin \varphi)+2 c \cos \varphi}{2 \sin \varphi}\left[\left(\frac{r}{a}\right)^{\frac{2 \sin \varphi}{1-\sin \varphi}}-1\right] \\
& +\frac{1+\sin \varphi}{1-\sin \varphi}\left(\frac{r}{a}\right)^{\frac{2 \sin \varphi}{1-\sin \varphi}} P_{a}+\frac{2 c \cos \varphi}{1-\sin \varphi} \\
& u_{p}^{\prime}=\frac{C_{1} \rho^{2}+C_{2}+\frac{F v}{2 E} \rho^{2} \ln \rho-\frac{\rho^{2}(1+\mu)(1-2 \mu)}{r}\left(\sigma_{b}+P_{0}\right)}{E}
\end{aligned}
$$

When $r=a$, the equation is the characteristic of tunnel surrounding rock.

The plastic zone radius of tunnel rock mass can be obtained by Eqs. (6) and (8) with the radius of $r=\rho$.

When the tunnel liner structure is ideal closed impermeable material, the liner external water pressure is the surface force. If the tunnel liner structure is pervious material, and the permeability coefficient of these materials is much smaller than the permeability coefficient of rock mass and liner structure, the thickness ratio of rock mass is much thinner, so the seepage force in liner structure can be replaced by the external water pressure. Assuming that the liner structure is still in the elastic state, the tunnel stress and displacement formulas are as follows: 


$$
\begin{gathered}
\sigma_{\theta}^{s}=\frac{a^{2}\left(a_{1}^{2}+r^{2}\right)}{r^{2}\left(a^{2}-a_{1}^{2}\right)}\left(P_{a}+P_{1}\right) \\
\sigma_{r}^{s}=-\frac{a^{2}\left(a_{1}^{2}-r^{2}\right)}{r^{2}\left(a^{2}-a_{1}^{2}\right)}\left(P_{a}+P_{1}\right) \\
u^{s}=\frac{1-\mu_{s}^{2}}{E_{s} r}\left[\left(\frac{a_{1}^{2}+r^{2}}{a^{2}-a_{1}^{2}}\right)+\frac{\mu_{s}}{1-\mu_{s}}\left(\frac{a_{1}^{2}-r^{2}}{a^{2}-a_{1}^{2}}\right)\right]\left(P_{a}+P_{1}\right) a^{2}+\Delta u
\end{gathered}
$$

When $r=a$, the equation is the support characteristic curve equation.

where $a_{1}$ is the inner diameter of the tunnel liner, $a$ is the outer diameter of the tunnel liner, $P_{a}$ is the liner support reaction, $\Delta u$ is the released displacement of tunnel wall before supporting, $E_{s}$ is the elastic modulus of liner structure, $\mu_{s}$ is the Poisson ratio of the liner structure.

\section{Conclusion}

Based on the theory of seepage mechanics and elastic-plastic theory, the stress state of tunnel rock mass under the coupling of seepage field and stress field is analyzed, the formula for calculating the radius of plastic zone, the stress and displacement of the rock mass in the elastic-plastic state are derived. The stress and displacement of tunnel surrounding rock and the mechanical characteristics of the supporting structure are analyzed under the condition of seepage.

\section{Acknowledgement}

In this paper, the research was sponsored by the Special Fund for Basic Scientific Research of Central Colleges of Chang'an University (Project No. 310821165011).

\section{References}

[1] Paul Bosasart, Peter M. Meier, Andreas Moeri, et al. Geological and hydraulic characterization of the excavation disturbed zone in the Opalinus Clay of the Mont Terri Rock Laboratory [J]. Engineering Geology, 2002, 66: 19-38.

[2] Bobet. Effect of pore water pressure on tunnel support during static and seismic loading [J]. Tunnelling and Underground Space Technology, 2003, 18(4): 377-393.

[3] WANG Xinghua, ZHANG Min, WANG Suixin. Theoretical solutions and analysis of submarine Tunnel in strain-softening surrounding rock considering the seepage force [J]. Rock and Soil Mechanics, 2009, 11(5): 3267-3272.

[4] ZOU Jinfeng, LI Shuaishuai, ZHANG Yong, et al. Theoretical solution and analysis of circular tunnel for the strain-softening rock mass considering the axial in situ stress and seepage forc e[J]. Chinese Journal of Theoretical and Applied Mechanics, 2014, 46(5): 747-755.

[5] ZOU Jinfeng, LI Shuaishuai, XU Yuan, et al. Theoretical solutions for a circular opening in an elastic-brittle-plastic rock mass incorporating the out-of-plane stress and seepage force [J]. KSCE Journal of Civil Engineering, 2016, 20(2): 687-701. 